\title{
Inhaled Iloprost as a First-Line Therapy for Persistent Pulmonary Hypertension of the Newborn
}

\author{
Seung Hyun Kim, MD, Hyun Ju Lee, PhD, Nam Su Kim, PhD, and Hyun-Kyung Park, PhD
}

Department of Pediatrics, Hanyang University College of Medicine, Seoul, Korea

\section{ABSTRACT}

Purpose: Persistent pulmonary hypertension of the newborn (PPHN) is a potentially fatal disease. Inhaled iloprost, a stable analogue of prostacyclin, has recently been used as a therapeutic option. However, there are no clinical guidelines on the use of iloprost, specifically for neonates. This study aimed to suggest the use of inhaled iloprost as a rescue therapy for PPHN based on our experience.

Methods: The efficacy and adverse events of inhaled iloprost were evaluated prospectively in nine full-term neonates with PPHN. We monitored the following parameters: fraction of inspired oxygen $\left(\mathrm{FiO}_{2}\right)$, respiratory severity score (RSS), heart rate, and mean blood pressure.

Results: The inhalation dose was 1 to $2 \mu \mathrm{g} / \mathrm{kg}$ initially, and 4 to 8 inhalations per day were applied over 2 to 8 days, except in the case of one neonate who died 2 days after birth. Echocardiographic findings, changes in $\mathrm{FiO}_{2}$, and $\mathrm{RSS}$ improved within the next 7 days in eight of the nine patients. Severe side effects on heart rate and blood pressure were not observed.

Conclusion: Our experience suggests that inhaled iloprost can be used as a first-line treatment in newborn infants with PPHN when inhaled nitric oxide is not available. To the best of our knowledge, this report is the first prospective case series on the use of inhaled iloprost in PPHN.

Key Words: Inhaled iloprost; Prostacyclin; Persistent fetal circulation syndrome

\section{INTRODUCTION}

Persistent pulmonary hypertension of the newborn (PPHN) is a serious disorder that results from the failure of normal pulmonary vascular adaptation at or soon after birth, and its estimated incidence is approximately 2 per 1,000 live births ${ }^{1)}$. High-frequency ventilation, inhaled nitric oxide (iNO), and extracorporeal membrane oxygenation have improved outcomes. However, several facilities do not offer these therapies due to their high costs and insufficient infrastructure. Furthermore, the Food and Drug Administration (FDA) recently issued a warning regarding the use of sildenafil to treat pediatric pulmonary arterial hypertension after an unexpectedly high mortality rate was observed among children
Received: 27 March 2019

Revised: 16 September 2019

Accepted: 15 October 2019

Correspondence to: Hyun-Kyung Park, PhD

Department of Pediatrics, Hanyang University College of Medicine, 222-1 Wangsimni-ro, Seongdong-gu, Seoul 04763, Korea

Tel: +82-2-2290-8397

Fax: +82-2-2297-2380

E-mail: neopark@hanyang.ac.kr

Copyright(c)

By Korean Society of Neonatology.

All right reserved.

This is an Open-Access article distributed under the terms of the Creative Commons Attribution Non-Commercial License (http://creativecommons.org/licenses/ by-nc/4.0), which permits unrestricted non-commercial use, distribution, and reproduction in any medium, provided the original work is properly cited. 
receiving the drug in high doses in a clinical trial ${ }^{2)}$.

Therefore, there is a significant need for new, alternative modalities to treat PPHN in neonates. Inhaled iloprost, a stable analogue of prostacyclin ( $\mathrm{PGI}_{2}$ ), may be an adjunctive or rescue therapy option for infants with PPHN. However, case reports regarding its use as an emergency treatment for PPHN are still preliminary $^{3-7)}$.

In our center, we used iloprost and other medications to treat PPHN at a time when iNO was not available because medically approved NO gas (iNOmax) was not yet introduced in Korea, and for other NO gases, we were not convinced of their safety. This report aimed to describe the effects of rescue attempts with inhaled iloprost on mechanically ventilated PPHN patients. Additionally, we have evaluated the therapeutic efficacy and safety of inhaled iloprost for the treatment of PPHN when inhaled iNO was not available.

\section{MATERIALS AND METHODS}

\section{Perinatal characteristics of the case series}

We prospectively enrolled nine full-term neonates ( $\geq 37$ weeks' gestation) with idiopathic or associated pulmonary arterial hypertension in this iloprost inhalation trial at the neonatal intensive care unit of Hanyang University Medical Center between March 2009 and August 2013. Neonates were excluded if they met one of the following criteria: (1) oxygenation index $>25$, assessed using an arterial blood gas analyzer; (2) need for immediate cardiopulmonary resuscitation; (3) presence of congenital heart disease; or (4) hemodynamic instability (mean arterial pressure $<5$ th percentile for their age). The respiratory severity score (RSS) was calculated by multiplying the fraction of inspired oxygen $\left(\mathrm{FiO}_{2}\right)$ by the mean airway pressure.

\section{Diagnosis of persistent pulmonary hypertension of the newborn}

PPHN was defined based on a combination of clinical and echocardiographic characteristics, including profound cyanosis and a preductal to postductal difference $(>5 \%)$ in transcutaneous oxygen saturation. Serial echocardiography was performed by the same skilled pediatric cardiologist (N.S.K.) based on clinical conditions and oxygenation status. The pulmonary arterial pressure, tricuspid regurgitation, $\mathrm{D}$-shaped left ventricle due to right ventricular dilatation, and bidirectional or right-to-left shunt through both the patent ductus arteriosus (PDA) and patent foramen ovale (PFO) were evaluated.

\section{Iloprost dosage and administration}

Inhaled iloprost (20 $\mu \mathrm{g} / 2 \mathrm{~mL}$, Ventavis, Bayer, Leverkusen, Germany) was administered at an initial dosage of 1 to $2 \mu \mathrm{g} /$ $\mathrm{kg}$ by integrating a nebulizer into the ventilator system without disconnecting the mechanical ventilator. The initial dosage was calculated to achieve a previously reported theoretical alveolar deposition $^{8)}$. One ampoule of iloprost was diluted with 4 to $6-\mathrm{mL}$ of distilled water. We used the PARI BOY SX type 085 (Pari GmbH, Starnberg, Germany) nebulizer for high-frequency oscillation and the Servo Ultra Nebulizer (Maquet, Solna, Sweden) for the Servo-i ventilator.

\section{Outcomes}

The efficacy of iloprost was compared before and 24, 48, 72 hours, and 1 week after the use of inhalation with echocardio graphic findings, RSS, and FiO2. Serial echocardiography was performed according to the patients' situation or on-duty status of the medical staff. Bronchoconstriction, which was a known adverse effect of iloprost, was also observed by the medical staff. Each single inhalation lasted over 10 minutes and was repeated every 3 to 4 hours, based on decreases in the postductal arterial saturation from the value immediately following the previous iloprost inhalation. The medication and ventilator settings were maintained unchanged during inhalation.

\section{Statistical analysis}

Statistical analysis was performed using the SPSS version 16.0 (SPSS, Chicago, IL, USA). All variables were expressed as the mean \pm standard deviation, and the Wilcoxon signed-rank test was used to compare respiratory and hemodynamic changes before and after the start of iloprost. Differences were considered significant when $P$-value was $<0.05$.

\section{RESULTS}

The demographic and clinical characteristics of the patients are presented in Table 1. All nine full-term neonates were referred from primary care, and six were boys. The median gestational age and birth weight were $38^{+4}$ weeks $\left(37^{+1}\right.$ to $\left.40^{+2}\right)$ and $3.42 \mathrm{~kg}(2.84$ to 4.39 ), respectively. Three patients were born by spontaneous 
vaginal delivery, and six were delivered by cesarean section. Severe respiratory failure caused by meconium aspiration syndrome, sepsis, asphyxia, and respiratory distress syndrome were associated with the pathogenesis of PPHN. Patient no. 8 was transferred after recurrence of PPHN due to aspiration pneumonia noted at the age of 21 days.

Iloprost was inhaled at an initial dose of 1 to $2 \mu \mathrm{g} / \mathrm{kg} /$ day and subsequently administered every 3 to 6 hours for 2 to 8 days in survivors by connecting an ultrasonic nebulizer to the inspiratory limb of the ventilator circuit. Inotropic support with dopamine and dobutamine was started to maintain systemic blood pressure at normal values for gestational ages in five patients ${ }^{1)}$. Surfactant administration and oral sildenafil were combined with iloprost in five and eight patients, respectively. The dose of oral sildenafil for each patient ranged from 1.0 to $2.8 \mathrm{mg} / \mathrm{kg} /$ dose.

Fentanyl and midazolam sedation was administered in six patients who showed intolerance to mechanical ventilation (Table 1). Table 2 describes the two-dimensional echocardiographic findings before and after treatment with iloprost. Echocardiography demonstrated a right-to-left shunt or a bidirectional shunt through the PDA or PFO. The inhalation of aerosolized iloprost showed not only a permanent conversion of the initial right-to-left shunting or bidirectional shunt, which leads to a substantial improvement in oxygenation, but also a simultaneous decrease in right ventricular pressure.

Aerosolized iloprost decreased $\mathrm{FiO}_{2}$ and improved oxygen saturation in eight of the nine patients, who normalized to baseline values within 1 week after iloprost. $\mathrm{FiO}_{2}$ decreased by $32 \%$, from $0.63 \pm 0.17$ (pre-iloprost) to $0.43 \pm 0.20$ (24 hours after iloprost; $P=0.007$ ) (Figure 1A). RSS decreased from $11.0 \pm 2.6$ to $8.7 \pm 2.3$ at 24 hours after iloprost $(P=0.011)$ (Figure $1 B)$. The use of iloprost in the emergency treatment of pulmonary hypertension was associated with a lifesaving clinical improvement with no evidence of side effects in eight of the nine patients. There were no significant changes in heart rate and mean blood pressure after iloprost inhalation (Figure 2). Moreover, no adverse effects that could be attributed to iloprost were observed.

Details of the outcomes after iloprost inhalation therapy are shown in Table 3. All patients were supported by high-frequency oscillation ventilation or pressure-controlled ventilation. The mean duration of oxygen therapy was $8.4 \pm 3.0$ days. Enteral feeding was started in infants who were at least 6 days old, and the number of days to full enteral feeding was $9.4 \pm 1.3$ days, ranging from 8 to 11 days. Eight of the nine patients made a full recovery

Table 1. Baseline Characteristics of Persistent Pulmonary Hypertension of the Newborn Patients Who Received Iloprost Inhalation

\begin{tabular}{|c|c|c|c|c|c|c|c|c|c|}
\hline \multirow{2}{*}{ Characteristic } & \multicolumn{9}{|c|}{ Patient } \\
\hline & 1 & 2 & 3 & 4 & 5 & 6 & 7 & 8 & 9 \\
\hline Gestational age (wk) & $40^{+2}$ & $40^{+0}$ & $39^{+5}$ & $40^{+0}$ & $37^{+1}$ & $38^{+3}$ & $39^{+1}$ & $39^{+3}$ & $38^{+5}$ \\
\hline Sex & M & M & M & $\mathrm{F}$ & M & M & M & $\mathrm{F}$ & $\mathrm{F}$ \\
\hline Birth weight (g) & 2,840 & 3,000 & 3,900 & 3,500 & 3,780 & 3,020 & 3,110 & 4,390 & 3,280 \\
\hline Cesarean section & - & + & - & - & + & + & + & + & + \\
\hline Etiologies of PPHN & $\begin{array}{c}\text { Early-onset } \\
\text { sepsis }\end{array}$ & RDS & MAS & RDS & Idiopathic & Idiopathic & $\begin{array}{c}\text { Birth } \\
\text { asphyxia }\end{array}$ & $\begin{array}{c}\text { Previous } \\
\text { PPHN }\end{array}$ & RDS \\
\hline Age at referral & D1 & D1 & D0 & D0 & D2 & D1 & D0 & D21 & D0 \\
\hline Maximum oxygenation index before iloprost & 24 & 13.3 & 10.5 & 13.5 & 15.5 & 3.9 & 13 & 18.5 & 7 \\
\hline \multicolumn{10}{|l|}{ Inhaled iloprost } \\
\hline Initial dose, age of start & $1, \mathrm{D} 2$ & $1, \mathrm{D} 1$ & $1, \mathrm{D} 3$ & $1, \mathrm{D} 2$ & $1, \mathrm{D} 2$ & $2, \mathrm{D} 1$ & $2, \mathrm{D} 1$ & $1, \mathrm{D} 22$ & $1, \mathrm{D} 2$ \\
\hline No. of inhalations (d) & 6 & 24 & 6 & 6 & 8 & 4 & 4 & 8 & 6 \\
\hline Accumulated doses $(\mu \mathrm{g} / \mathrm{kg})$ & 9 & 20 & 23 & 14 & 11 & 33 & 48 & 27 & 42 \\
\hline Duration of treatment $(\mathrm{d})$ & 2 & 2 & 4 & 3 & 3 & 6 & 8 & 4 & 5 \\
\hline Inotropics & + & + & - & - & + & + & - & - & + \\
\hline Surfactant & - & + & + & + & + & - & - & - & + \\
\hline Oral sildenafil, age of start & - &,$+ \mathrm{D} 1$ &,$+ \mathrm{D} 1$ &,$+ \mathrm{D} 3$ &,$+ \mathrm{D} 3$ &,$+ \mathrm{D} 1$ &,$+ \mathrm{D} 1$ &,+ D22 &,$+ \mathrm{D} 2$ \\
\hline Sedative & + & + & - & - & + & + & + & + & + \\
\hline Survival & Yes & Expired on D2 & Yes & Yes & Yes & Yes & Yes & Yes & Yes \\
\hline
\end{tabular}

Abbreviations: PPHN, persistent pulmonary hypertension of the newborn; RDS, respiratory distress syndrome; MAS, meconium aspiration syndrome; D, days of age. 
Table 2. Echocardiographic Pretreatment and Posttreatment Findings* with Inhaled Iloprost

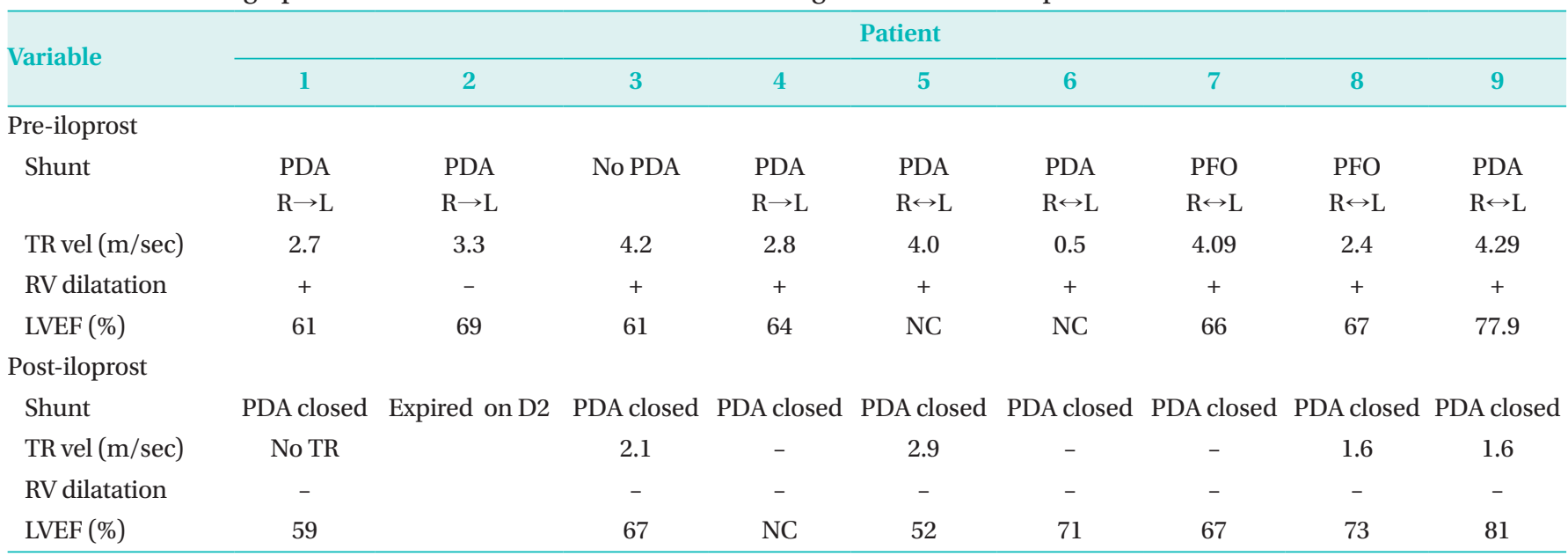

*Serial echocardiography was performed at the beginning of clinical improvement in each patient.

Abbreviations: PDA, patent ductus arteriosus; $\mathrm{R} \rightarrow \mathrm{L}$, right to left shunt; $\mathrm{R} \leftrightarrow \mathrm{L}$, bidirectional shunt; PFO, patent foramen ovale; $T R$ vel, tricuspid regurgitation velocity; $\mathrm{RV}$, right ventricle; $\mathrm{LVEF}$, left ventricular ejection fraction; $\mathrm{NC}$, not checked; $\mathrm{D}$, days of age.

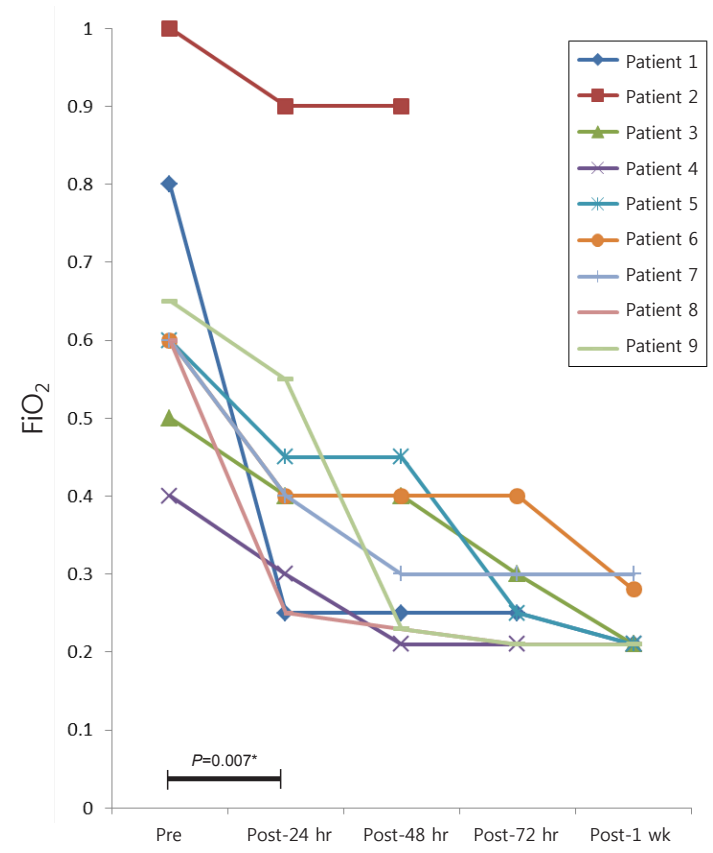

A

Time

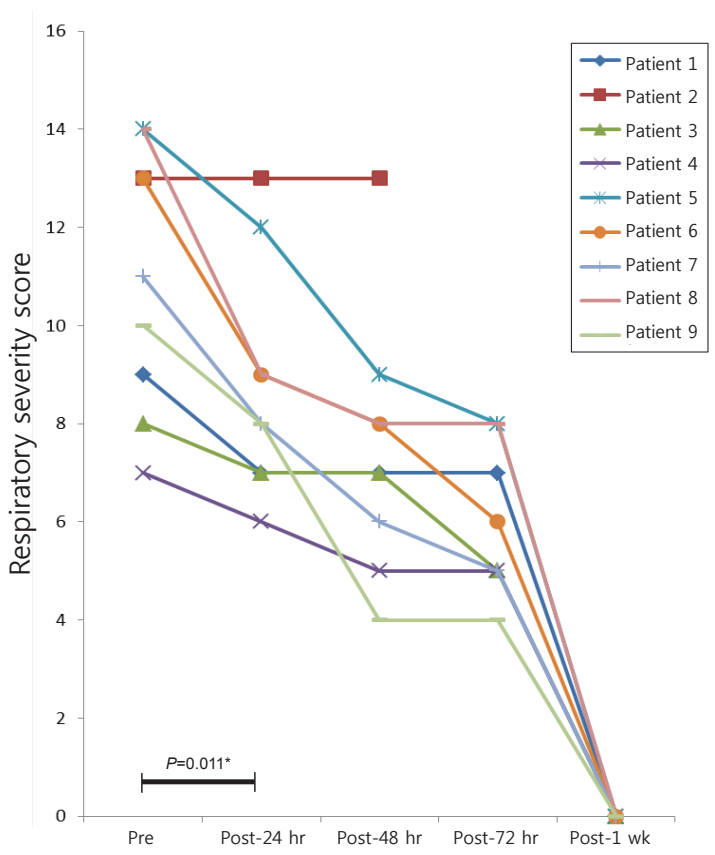

B

Figure 1. (A) Changes in the fraction of inspired oxygen $\left(\mathrm{FiO}_{2}\right)$ values before and during iloprost therapy in neonates with persistent pulmonary hypertension of the newborn. (B) The changes in respiratory severity score before and after inhaled iloprost therapy in neonates with persistent pulmonary hypertension of the newborn. ${ }^{*} P$-value between before and 24 hours after iloprost; ${ }^{\dagger}$ Expired during therapy. Abbreviations: Pre, before the use of iloprost; Post, after the use of iloprost.

and were discharged from the hospital within 3 weeks, ranging from 10 to 18 days. However, one patient with severe hypoxic damage and multi-organ failure when he was referred showed a tension pneumothorax in both sides of the lungs and a large PDA. He died due to a lack of response to treatment 2 days after his birth.

\section{DISCUSSION}

The main reason why inhaled iloprost is more preferred than iNO is its readily availability and comparable clinical effects, while iNO is cost prohibitive and requires special monitoring for side 

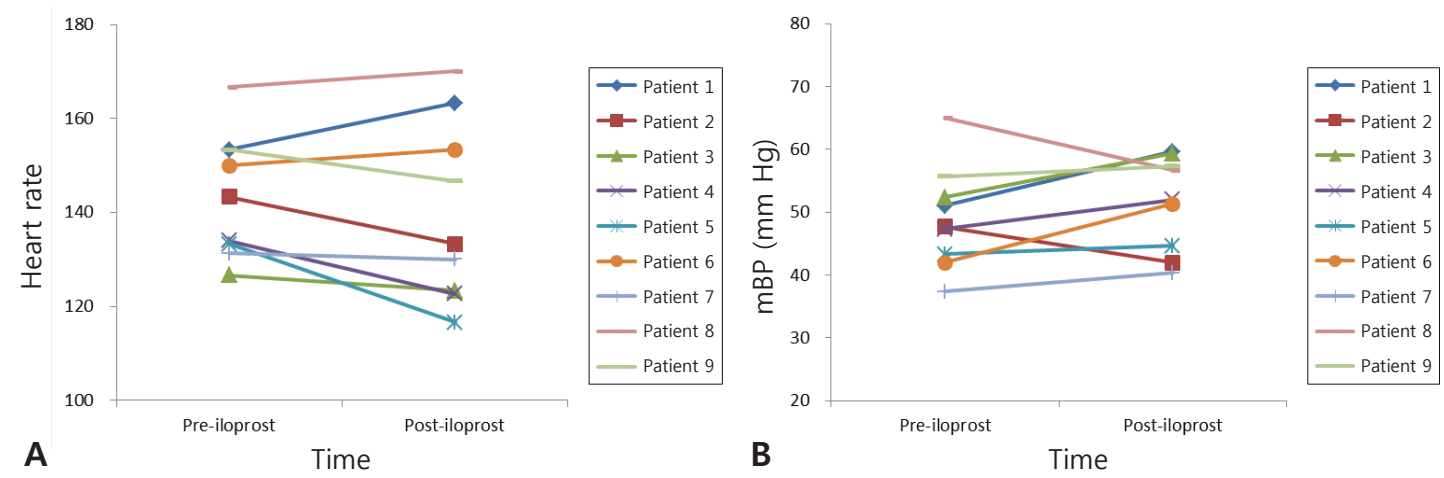

Figure 2. (A) Heart rate and (B) mean blood pressure (mBP) trends before and 24 hours after the start of iloprost therapy. $P$-values between timepoints are insignificant.

Table 3. Outcomes after Iloprost Inhalation Therapy

\begin{tabular}{|c|c|c|c|c|c|c|c|c|c|}
\hline \multirow{2}{*}{ Variable } & \multicolumn{9}{|c|}{ Patient } \\
\hline & 1 & 2 & 3 & 4 & 5 & 6 & 7 & 8 & 9 \\
\hline Ventilator (d) & 3 & Expired on D2 & 7 & 5 & 5 & 7 & 5 & 5 & 8 \\
\hline $\mathrm{O}_{2}$ therapy $(\mathrm{d})$ & 4 & & 14 & 8 & 6 & 10 & 8 & 7 & 10 \\
\hline Air leak & - & + & - & - & - & - & - & - & - \\
\hline Enteral feeding start (d of age) & 3 & & 5 & 4 & 5 & 6 & 4 & 3 & 5 \\
\hline Days to full enteral feeding $(100 \mathrm{cc} / \mathrm{kg} / \mathrm{d})$ & 9 & & 11 & 8 & 10 & 11 & 8 & 8 & 10 \\
\hline Hospitalization (d) & 11 & & 18 & 10 & 12 & 15 & 12 & 11 & 11 \\
\hline
\end{tabular}

Abbreviation: $\mathrm{D}$, days of age.

effects. However, there is limited experience regarding inhaled iloprost therapy, specifically in neonates. Our study suggests that inhaled iloprost is a feasible therapy for mechanically ventilated neonates with PPHN. No clinically significant complications were observed during the nebulization of iloprost, and we achieved significant oxygenation and hemodynamic improvements.

PPHN is a complex clinical syndrome with significant morbidity and mortality ${ }^{9}$. iNO, inhaled iloprost, and phosphodiesterase inhibitors (sildenafil) are known treatment options that are used along with supportive care such as alkalinization and highfrequency oscillatory ventilation in neonates with PPHN. iNO has a selective effect on the pulmonary vasculature through the guanosine 3,5'-cyclic monophosphate and has become well established as the first-line therapy for PPHN ${ }^{10,11)}$. However, iNO therapy is still unavailable in many developing countries. Although pulmonary hypertension in adults is commonly treated with $\mathrm{PGI}_{2}$ analogues (treprostinil, iloprost, or epoprostenol), endothelin receptor antagonists (bosentan and ambrisentan), and phosphodiesterase type 5 inhibitors (sildenafil) ${ }^{12}$, few reports have addressed the use of these treatments in neonates and preterm infants $^{3,4,13-177}$. The pharmacokinetics of oral sildenafil in neonates with decreased gastric motility remain uncertain. Moreover, the FDA issued a warning regarding the pediatric-specific side effects of sildenafil, including hypotension and hemoptysis ${ }^{2)}$. Therefore, there is an increasing interest in the potential benefit of inhaled iloprost in neonates. In 2014, Kahveci et al. ${ }^{18)}$ compared the effectiveness and safety of oral sildenafil and inhaled iloprost therapy for PPHN in a referral center located in a low-income re gion of Turkey. Results showed that iloprost was considered to be more effective than sildenafil in the treatment of PPHN with regard to time to clinical response, ventilator/respiratory parameters, and combined drug administration ${ }^{18)}$. However, it seems to be impossible to evaluate the isolated effects of both drugs in the clinical field due to ethical issues.

Iloprost is a PGI2 analogue, and PGI2 is a member of the prostanoid group of eicosanoids, which regulate homeostasis, smooth muscle function, and inflammation ${ }^{19)}$. $\mathrm{PGI}_{2}$ is produced by endothelial cells and influences several cardiovascular processes by increasing adenosine 3,'5'-cyclic monophosphate levels. This mechanism could explain the beneficial effect of iloprost on nonresponders to inhaled iNO and the additive effect of combining both agents ${ }^{11)}$. Several drawbacks are encountered regarding the clinical applications of inhaled iloprost in neonates. There are insufficient prospective clinical studies, practical difficulties 
of aerosolized application into a mechanical ventilator, and uncertainties about optimal dosage and the time to achieve a significant effect in neonates ${ }^{5,7)}$. Han et al. ${ }^{20)}$ reported the therapeutic effect of inhaled iloprost in newborn infants with severe PPHN refractory to iNO but enrolled only a small number of cases retrospectively. Although clinical data are few, inhaled iloprost, single or combined, has been useful and effective as a rescue or additional treatment for improving oxygenation in cases of acute pulmonary hypertension in children, bronchopulmonary dysplasia, postoperative pulmonary hypertensive crisis in children with congenital heart disease, and pulmonary hypertension in preterm infants in addition to $\mathrm{PPHN}^{4,8,11,15,16,21)}$.

Our study could provide useful guidelines on the clinical trials of inhaled iloprost in terms of available dosage and the timing of inhaled iloprost for neonates. Moreover, iloprost might be an alternative drug treatment that improves oxygenation in the absence of iNO. Adverse effects of bronchoconstriction or unstable hemodynamics such as hypotension have sometimes been observed during iloprost nebulization in older children ${ }^{13)}$. However, compared to that with the systemic application of $\mathrm{PGI}_{2}{ }^{22)}$, the rate of adverse effects with iloprost seems to be negligible. In our study, adverse effects were not observed.

This study has several limitations, that is, the total number of cases may be considered insufficient and they were all from a single center. Given that a control group is not set up, we cannot exclude the positive effects from other applied drugs such as a surfactant and sildenafil.

In conclusion, our clinical experience supports that nebulized iloprost, with or without concomitant oral sildenafil, is a safe and promising therapy for PPHN, specifically when inhaled NO is unavailable. However, larger controlled studies are required to confirm the clinical usefulness of inhaled iloprost and to define its safety and efficacy alone or in combination with other vasodilator drugs.

\section{ARTICLE INFORMATION}

\section{Ethical statement}

The study was approved by Institutional Review Board (IRB) of Hanyang University Medical Center (IRB No. 2015-05-027-009). Written informed consent was obtained from the parents of every neonate before their enrollment in the study.

\section{Conflicts of interest}

No potential conflict of interest relevant to this article was reported.

\section{Author contributions}

Conception or design: H.K.P.

Acquisition, analysis, or interpretation of data: H.J.L., N.S.K.

Drafting the work or revising: S.H.K.

Final approval of the manuscript: S.H.K., H.K.P.

\section{ORCID}

Seung Hyun Kim https://orcid.org/0000-0002-5740-5688

Hyun-Kyung Park https://orcid.org/0000-0001-5956-9208

\section{Acknowledgments}

This research was supported by the Korea Special Therapeutic Education Center (Chairman Il-Kewon Kim) of Anyang, Korea.

\section{REFERENCES}

1. Nair J, Lakshminrusimha S. Update on PPHN: mechanisms and treatment. Semin Perinatol 2014;38:78-91.

2. Maxey DM, Ivy DD, Ogawa MT, Feinstein JA. Food and Drug Administration (FDA) postmarket reported side effects and adverse events associated with pulmonary hypertension therapy in pediatric patients. Pediatr Cardiol 2013;34:1628-36.

3. Ehlen M, Wiebe B. Iloprost in persistent pulmonary hypertension of the newborn. Cardiol Young 2003;13:361-3.

4. Avila-Alvarez A, Bravo-Laguna MC, Bronte LD, Del Cerro MJ. Inhaled iloprost as a rescue therapy for transposition of the great arteries with persistent pulmonary hypertension of the newborn. Pediatr Cardiol 2013;34:2027-9.

5. De Luca D, Zecca E, Piastra M, Romagnoli C. Iloprost as 'rescue' therapy for pulmonary hypertension of the neonate. Paediatr Anaesth 2007;17:394-5.

6. Yilmaz O, Kahveci H, Zeybek C, Ciftel M, Kilic O. Inhaled iloprost in preterm infants with severe respiratory distress syndrome and pulmonary hypertension. Am J Perinatol 2014;31: 321-6.

7. Chotigeat U, Jaratwashirakul S. Inhaled iloprost for severe persistent pulmonary hypertension of the newborn. J Med Assoc Thai 2007;90:167-70.

8. Limsuwan A, Wanitkul S, Khosithset A, Attanavanich S, Samankatiwat P. Aerosolized iloprost for postoperative pulmonary hypertensive crisis in children with congenital heart disease. Int J Cardiol 2008;129:333-8.

9. Shah PS, Ohlsson A. Sildenafil for pulmonary hypertension in 
neonates. Cochrane Database Syst Rev 2007;3:CD005494.

10. Dhillon R. The management of neonatal pulmonary hypertension. Arch Dis Child Fetal Neonatal Ed 2012;97:F223-8.

11. Kirbas A, Yalcin Y, Tanrikulu N, Gurer O, Isik O. Comparison of inhaled nitric oxide and aerosolized iloprost in pulmonary hypertension in children with congenital heart surgery. Cardiol J 2012;19:387-94.

12. Badesch DB, Abman SH, Simonneau G, Rubin LJ, McLaughlin VV. Medical therapy for pulmonary arterial hypertension: updated ACCP evidence-based clinical practice guidelines. Chest 2007;131:1917-28.

13. Piastra M, De Luca D, De Carolis MP, Tempera A, Stival E, Caliandro F, et al. Nebulized iloprost and noninvasive respiratory support for impending hypoxaemic respiratory failure in for merly preterm infants: a case series. Pediatr Pulmonol 2012;47: 757-62.

14. Eifinger F, Sreeram N, Mehler K, Huenseler C, Kribs A, Roth B. Aerosolized iloprost in the treatment of pulmonary hypertension in extremely preterm infants: a pilot study. Klin Padiatr 2008;220:66-9.

15. Hwang SK, O YC, Kim NS, Park HK, Yum MK. Use of inhaled iloprost in an infant with bronchopulmonary dysplasia and pulmonary artery hypertension. Korean Circ J 2009;39:343-5.

16. Gurakan B, Kayiran P, Ozturk N, Kayiran SM, Dindar A. Thera- peutic combination of sildenafil and iloprost in a preterm neonate with pulmonary hypertension. Pediatr Pulmonol 2011;46: 617-20.

17. Mohamed WA, Ismail M. A randomized, double-blind, placebocontrolled, prospective study of bosentan for the treatment of persistent pulmonary hypertension of the newborn. J Perinatol 2012;32:608-13.

18. Kahveci H, Yilmaz O, Avsar UZ, Ciftel M, Kilic O, Laloglu F, et al. Oral sildenafil and inhaled iloprost in the treatment of pulmonary hypertension of the newborn. Pediatr Pulmonol 2014; 49:1205-13.

19. Majed BH, Khalil RA. Molecular mechanisms regulating the vascular prostacyclin pathways and their adaptation during pregnancy and in the newborn. Pharmacol Rev 2012;64:540-82.

20. Han YK, Lee SM, Eun HS, Kim JE, Namgung R, Park MS, et al. The therapeutic effect of inhaled iloprost in newborn infants with severe persistent pulmonary hypertension refractory to inhaled nitric oxide. Korean J Perinatol 2011;22:57-63.

21. Mulligan C, Beghetti M. Inhaled iloprost for the control of acute pulmonary hypertension in children: a systematic review. Pediatr Crit Care Med 2012;13:472-80.

22. Eronen M, Pohjavuori M, Andersson S, Pesonen E, Raivio KO. Prostacyclin treatment for persistent pulmonary hypertension of the newborn. Pediatr Cardiol 1997;18:3-7. 